\title{
Black First-Year College Students' Alcohol Outcome Expectancies
}

By: Shemeka Thorpe, Amanda E. Tanner, Samuella Ware, Kate Guastaferro, Jeffrey J. Milroy, and David L. Wyrick

Thorpe, S., Tanner, A. E., Ware, S., Guastaferro, K., Milroy, J. J., \& Wyrick, D. L. (2020). Black First-Year College Students' Alcohol Outcome Expectancies. American Journal of Health Education, 51(2), 78-86. https://doi.org/10.1080/19325037.2020.1713259

This is an Accepted Manuscript of an article published by Taylor \& Francis in American Journal of Health Education on 30 January 2020, available online: http://www.tandfonline.com/10.1080/19325037.2020.1713259.

\begin{abstract}
***(C) 2020 SHAPE America. Reprinted with permission. No further reproduction is authorized without written permission from Taylor \& Francis. This version of the document is not the version of record. Figures and/or pictures may be missing from this format of the document. ***
\end{abstract}

\begin{abstract}
:
Background: Alcohol outcome expectancies (AOEs) are associated with college students' varied alcohol consumption. Existing research on AOEs focuses primarily on heterosexual White students. Thus, it is important to explore how the intersection of multiple identities such as race, gender, and sexual orientation influence the endorsement of specific AOEs. Purpose: This paper examines AOEs among Black first-year college students, with specific attention to the influence of gender and sexual orientation. Methods: Participants were 307 Black students from four universities in the United States. We conducted bivariate analyses using the 2-factor and 4-factor B-CEOA scale. Results: Most students did not hold positive AOEs such as tension reduction and sexual enhancement. Students were more likely to endorse negative AOEs such as behavioral and cognitive impairment and social risk. Discussion: Black first-year college students reported more negative expectations associated with alcohol use, including those related to negative social risks and consequences. Thus, AOEs may serve as a protective factor against alcohol use among Black college students. Translation to Health Education Practice: Alcohol interventions should be tailored to focus on the intersection of race, gender, and sexual orientation. Culturally relevant alcohol interventions have the potential to reduce the immediate and long-term consequences of alcohol use.
\end{abstract}

Keywords: alcohol outcome expectancies | Black college students | alcohol interventions

\section{Article:}

\section{Background}

The transition from high school to college has been recognized as a period of time when students experience more freedom and take greater risks, including increased alcohol consumption. ${ }^{1,2}$ The National Institute on Alcohol Abuse and Alcoholism identified first-year college students as a 
risk group for heavy episodic drinking (i.e., $\leq 4$ drinks for females and $\leq 5$ drinks for males on the same occasion) compared to the general college population. ${ }^{3}$ On average more than $42 \%$ of firstyear college students reported one or more episodes of heavy episodic drinking in the past month. ${ }^{4-6}$ Heavy episodic drinking in college can lead to a variety of preventable negative health outcomes, including alcohol poisoning, interpersonal violence, sexually transmitted infections (STIs), car accidents, and alcohol dependency into adulthood. ${ }^{7,8}$ There are a variety of reasons postulated for students' motivations to drink alcohol including social environments, descriptive and injunctive norms, and alcohol outcome expectancies (AOEs) ${ }^{9,10}$ AOEs are formulated by students' direct and indirect experiences with alcohol ${ }^{11}$ An individual's expectation about the positive and negative effects of alcohol helps determine the likelihood, amount, and frequency of alcohol consumption. ${ }^{12,13}$ Positive AOEs, such as tension reduction, disinhibition, social assertiveness, and sexual enhancement, have been linked to increases in alcohol use during the first year of college. ${ }^{4,14}$ AOEs are regarded as the strongest predictor of alcohol use during the first year of college. ${ }^{4,14}$ However, negative AOEs have the potential to serve as protective factors against alcohol consumption and lead to lower rates of alcohol use.

\section{Black college students' AOEs}

Heavy episodic drinking patterns vary by student demographics (e.g., race, gender, sexual orientation) ${ }^{10,15}$ Heavy episodic drinking is influenced by a system of culture and beliefs that may affect Black and White college students differently. ${ }^{16-18}$ For instance, Black college students are more likely to abstain from alcohol consumption, have longer periods of non-drinking, and are less likely to participate in heavy episodic drinking. ${ }^{19,20}$ Black college students' drinking behaviors are likely affected by having fewer friends who engage in heavy episodic drinking and perceptions that drinking occurs in spaces occupied primarily by White students (e.g. fraternity parties or bars), both serving as protective factors. ${ }^{19,21}$ Black college students avoid drinking in spaces where they will potentially encounter racism by intoxicated White students. ${ }^{22}$ Further, Black college students may refrain from drinking due to the intersecting double standards of race and gender. ${ }^{19}$ For instance, Black college men's negative description of women who participate in heavy episodic drinking may prevent Black women from drinking heavily. ${ }^{19}$ In these cases, Black students may be more likely to endorse negative AOEs than positive ones. ${ }^{23}$

Overall, $64 \%$ of first-year college students' hookups involved alcohol consumption. ${ }^{24}$ Black college students are less likely to hookup than their White counterparts, ${ }^{25}$ thus underscoring the importance of understanding Black college students' AOEs specific to sexual behaviors and perceptions of intimacy. This understanding is particularly crucial given the link between alcohol use and sexual risk behaviors, which can result in negative sexual health outcomes (e.g., STIs, $\mathrm{HIV}$, unintended pregnancies). ${ }^{26}$ One study focused solely on sex-related AOEs, found Black women believed that alcohol increased their pleasure, intensified their desire to give pleasure to their sexual partner, increased participation in a wider variety of sexual behaviors, including those they may not engage in while sober (e.g., condomless sex, having sex with a partner they usually would not have sex with, and having a one-night stand), and reduced the guilt of engaging in casual sex. ${ }^{27}$ Thus, Black college women might expect that consuming alcohol will enhance their sexual experiences, yet this may come at the expense of increased exposure to the potential negative consequences associated with alcohol consumption, such as increased STI transmission. Given the current sexual health disparities among Black college students, including 
higher rates of STIs, ${ }^{28}$ further work is needed to understand the role of AOEs on their health outcomes.

Intersecting identities and alcohol use

The utilization of an intersectional framework to understand AOEs and subsequent alcohol consumption among Black college students is critical for examining the complex social realities of this population. Intersectionality refers to the interconnected nature of social categories such as race, gender, and sexual identity of an individual with attention to the corresponding systems of oppression and disadvantage. ${ }^{29,30}$ Thus, an intersectional framework allows for exploring the compounding effects of race, gender, and sexual identity that may affect alcohol consumption. ${ }^{31,32}$ Research has shown that Black college students tend to drink to cope (drinking to reduce stress and negative affect) ${ }^{33-35}$ which rapidly escalates during the transition from adolescence to young adulthood and can lead to excessive alcohol use and alcohol-related problems into adulthood. ${ }^{36}$ Sexual orientation further complicates the alcohol behaviors of college students. Sexual minority students tend to drink more than heterosexual students, ${ }^{37,38}$ thus their expectancies for alcohol consumption require further exploration. This is particularly relevant for multi-marginalized students, like Black sexual minority college students, who have higher rates of STIs than their White counterparts. ${ }^{28}$ Examination of the intersection of race, gender, and sexual orientation may be useful in understanding how AOEs operate to facilitate or challenge alcohol use among Black first-year college students to inform relevant interventions.

Despite the potential negative sexual health outcomes associated with alcohol consumption prior to $\operatorname{sex}^{24,39,40}$ and Black populations higher rates of STIs and HIV,${ }^{28}$ limited research has focused on Black college students' AOEs. Understanding the AOEs of Black college students is useful for informing culturally relevant programming. Interventions focused on both alcohol and sexual health present the opportunity to reduce sexual health disparities, reduce alcohol consumption, and mitigate the longer term effects of use (e.g., cancers and cirrhosis). Since alcohol use and heavy episodic drinking are not as prevalent for Black college students, ${ }^{16-18,41}$ there is a need to understand what protective factors are associated with these differences including AOEs. Addressing alcohol expectancies can help recorrect the misguided positive expectancies for alcohol use, reframe the negative expectancies as an opportunity to reduce alcohol use, and provide suggestions on alcohol-free activities that elicit similar positive expectancies.

\section{Purpose}

The purpose of this analysis was to examine the AOEs of Black first-year college students by specifically examining three questions:

1. What AOEs are endorsed by Black first-year college students?

2. Do AOEs differ by engagement in individual behaviors such as alcohol use, hookups, and sexual behaviors?

3. Is there an association between AOEs and alcohol use?

\section{Methods}




\section{Participants}

This analysis included baseline data from the first optimization trial of the larger itMatters online STI and alcohol prevention intervention study that included 3,551 first-year students from four universities across the United States. For more detailed information about the intervention and procedures see Kugler et al. ${ }^{9}$ The sample for this analysis was limited to students who identified as Black $(\mathrm{N}=317)$. Students who identified as transgender and "other" $(n=2)$ were removed as their sample size was too small for analysis. Eight additional students were removed because they were not first-year students, resulting in a final analytic sample of 307 participants. Notably, these data were collected from students prior to exposure to the itMatters intervention. All procedures were approved by the University of North Carolina Greensboro Institutional Review Board.

\section{Procedures}

Baseline data were collected in 2017 from first-year students across four geographically diverse four-year universities, three of which were predominantly white institutions (PWIs) and one minority serving institution. Following consent, the online baseline survey took approximately 10-15 min for students to complete. Upon completion of the survey, students received a $\$ 5$ gift card.

\section{Measures}

\section{Demographics}

Participants were asked to report their gender (male, female, transgender, or other), their age, and their sexual orientation (heterosexual, bisexual, lesbian/gay, or other). For the purpose of the present analysis, sexual orientation was dichotomized as heterosexual (1) or sexual minority (0).

Lifetime alcohol use

Participants were asked to report how often they used alcohol in the past 30 days. Answers were coded as: I have never used alcohol (0), I have used alcohol but not in the past 30 days (1), and I have used alcohol in the past 30 days (2). For the present analysis, a dichotomous "lifetime alcohol use" variable was created by combining those who had ever consumed alcohol into one group. A "30 day alcohol use" dichotomized variable was also created. To identify recent heavy episodic drinkers, participants were asked to report how many times in the past 2 weeks they consumed four (females) or five (males) or more drinks in a row within the last 2 weeks. Anyone who said one or more times was considered to have participated in recent heavy episodic drinking.

Alcohol outcome expectancies

Positive and negative AOEs were assessed using the 15-item Brief Comprehensive Effects on Alcohol questionnaire (B-CEOA; $\alpha=.81)$, comprised of four subscales: risk and sociability ( 7 items; $\alpha=.74)$, cognitive and behavioral impairment (4 items; $\alpha=.71)$, sexuality ( 2 items; $\alpha=$ 
.74), and tension reduction ( 2 items; $\alpha=.76$ ) ${ }^{42,43}$ Negative expectations about the effects of alcohol use include cognitive and behavioral impairment (e.g., I would feel clumsy, I would feel dizzy). Positive expectations about the effects of alcohol use include items in sexuality (e.g. I would enjoy sex more), tension reduction (e.g., I would feel calm), and enhanced sociability (e.g., I would feel braving and daring and I would act sociable). Response options ranged on a 4point Likert scale from disagree (1) to agree (4). Mean scores were computed for each subscale. Since some subscales contain both positive and negative expectancies (i.e., risk and sociability), we followed existing analytic procedure ${ }^{43-45}$ and also created a 2-factor B-CEOA divided into positive ( 8 items; $\alpha=.82$ ) and negative expectancies ( 7 items; $\alpha=.78$ ) that have been used previously in other studies.

\section{Sexual behaviors}

Participants were asked to report the number of times they had oral, anal, or vaginal sex in the past 30 days. Answers were coded as: I have never had sex (1), I have had sex but not in the past 30 days (2), and I have had sex one or more times in the past 30 days (3). In the present analysis, a lifetime sexual behavior variable was dichotomized into those who reported ever having sex versus those who have not.

\section{Hookups}

Participants were asked how many times they engaged in a hookup in the past 30 days. A hook up was defined for participants as non-penetrative (kissing, touching, oral sex) and/or penetrative (vaginal, anal) behaviors with someone with whom you are not in a committed relationship (friends with benefits) or with someone you just met (one night stand). Answers were coded as: I have never had a hookup (1), I have had a hookup but not in the past 30 days (2), and I have had one or more hookups in the past 30 days (3). For the present analysis, a lifetime hookup variable was dichotomized into those who reported ever having a hookup versus those who have not.

Analytic plan

Descriptive statistics on sociodemographic variables were conducted and mean differences in AOEs by gender, sexual orientation, lifetime alcohol use, and sexual and hookup behaviors were analyzed through t-test and chi-square tests. In this analysis, we tested AOEs using both the 4factor and 2-factor scale (as described above). Differences in AOEs mean scores for sexual behavior and hookup participation were only analyzed using the sexuality subscale because it was the only scale that included expectancies on how alcohol would affect sexual experiences. A binary logistic regression was conducted to examine the relationship between AOEs and lifetime and 30-day alcohol use. Analyses were conducted using SPSS version 26.

\section{Results}

Demographics and behaviors

The majority of the sample identified as heterosexual $(\mathrm{n}=280,92.1 \%)$, female $(\mathrm{n}=214 ; 69.7 \%)$, were 18 years old $(n=217,88.3 \%)$, and attended a PWI $(n=288 ; 93.8 \%)$. Many participants 
had engaged in anal, oral, or vaginal sex in the last 30 days $(\mathrm{n}=139 ; 46.6 \%)$. Notably, 113 (36.8\%) participants had sex but not in the last 30 days and $46(15.4 \%)$ had never had sex. Overall, 133 (43.3\%) participants had never consumed alcohol, 98 (31.9\%) participants had consumed alcohol but not in the last 30 days, and 70 (23.3\%) consumed in the last 30 days. Only $23(7.6 \%)$ of students reported participation in heavy epiosidic drinking in the last 2 weeks. The majority of students $(n=194 ; 63.2 \%)$ reported no experience with a hookup $(n=61,20.5 \%)$ reported having had a hookup in the last 30 days, and $7(2.9 \%)$ reported having a hookup under the influence of alcohol. Demographic characteristics and behaviors are summarized in Table 1 by gender and sexual orientation.

Table 1. Characteristics of Black first-year college students $\mathrm{N}=307$.

\begin{tabular}{|l|c|c|c|c|}
\hline & \multicolumn{2}{|c|}{ Sexual orientation N (\%) } & \multicolumn{2}{c|}{ Gender N (\%) } \\
\hline & Heterosexual & Sexual minority & Male & Female \\
\hline Used alcohol in their lifetime & $153(55.4)$ & $12(54.5)$ & $40(43.5)$ & $128(61.2)$ \\
\hline Ever engaged in a hookup & $92(33.8)$ & $9(40.9)$ & $35(38.5)$ & $68(33)$ \\
\hline Had sex in their lifetime & $172(53)$ & $11(50)$ & $61(67)$ & $124(59.9)$ \\
\hline Used alcohol during last sex & $9(5.3)$ & $1(9.1)$ & $3(4.9)$ & $7(5.7)$ \\
\hline Used alcohol during last hookup & $6(6.6)$ & $1(12.5)$ & $3(8.6)$ & $4(6.1)$ \\
\hline Had an STI test within last 6 months & $83(30.6)$ & $6(28.6)$ & $24(26.7)$ & $66(32.2)$ \\
\hline
\end{tabular}

Only participants who reported ever having sexual intercourse were asked if they consumed alcohol before last sex. Only those who had a hookup were asked if they consumed alcohol during their last hookup.

\section{AOEs}

Mean scores were calculated for all of the alcohol outcome expectancies subscales (range 1-4). For the 4-factor scale: a mean score of $2.53(\mathrm{SD}=.70)$ was calculated for the risk and sociability subscale, $2.72(\mathrm{SD}=.74)$ for the cognitive and behavioral impairment subscale, 1.86 $(\mathrm{SD}=.88)$ on the sexuality subscale, and $2.28(\mathrm{SD}=.88)$ on the tension reduction subscale. Additionally, mean scores were calculated for the 2-factor scale; mean scores were 2.31 ( $\mathrm{SD}=$ $.68)$ for positive expectancies and $2.52(\mathrm{SD}=.68)$ for negative expectancies (see Table 2 ).

The results of the independent sample t-test revealed no significant differences in AOEs between females and males using the 4-factor or 2-factor scales. There were significant mean differences in AOEs by sexual orientation; in the 4-factor scale analyses, heterosexual students had significantly lower scores on risk and sociability expectancies $(\mathrm{M}=2.80, \mathrm{SD}=.67)$ than sexual minority students $(\mathrm{M}=2.49, \mathrm{SD}=.70)(t(284)=1.99, p=.048)$. In the 2-factor analyses, heterosexual students $(\mathrm{M}=2.28 ; \mathrm{SD}=.68)$ had significantly lower scores on positive expectancies than sexual minority students $(\mathrm{M}=2.64, \mathrm{SD}=.61)(\mathrm{t}(282)=-2.32, p=.021)$. Additionally, there were significant mean differences in AOEs by previous alcohol use (both lifetime and 30-day use) for all subscales in the 2-factor and 4-factor subscales: cognitive and behavioral impairment $(t(287)=2.30, p=.022)$, risk and sociability $(t(287)=-2.11, p=$ $.036)$, sexuality $(t(293)=-2.90, p=.004)$, tension reduction $(t(295)=-2.68, p=.008)$, positive expectancies $\mathrm{t}(285)=3.62, p<.001)$ and negative expectancies $\mathrm{t}(284)=-2.58, p=.01)$. Students who had never consumed alcohol had significantly higher cognitive and behavioral impairment scores $(\mathrm{M}=2.82, \mathrm{SD}=.80)$ than those who had consumed alcohol $(\mathrm{M}=2.62, \mathrm{SD}=.68)$. In addition, students who had consumed alcohol had significantly higher risk and sociability $(\mathrm{M}=$ $2.59, \mathrm{SD}=.67)$, sexuality $(\mathrm{M}=1.99, \mathrm{SD}=.89)$, and tension reduction $(\mathrm{M}=2.41, \mathrm{SD}=.82)$ 
scores than those who had never consumed alcohol $(\mathrm{M}=2.42, \mathrm{SD}=.74 ; \mathrm{M}=1.69, \mathrm{SD}=.84$; and $\mathrm{M}=2.15, \mathrm{SD}=.93$, respectively). Students that had never consumed alcohol endorsed more negative expectancies $(\mathrm{M}=2.58, \mathrm{SD}=.68)$ and less positive expectancies $(\mathrm{M}=2.23, \mathrm{SD}-.67)$ than those who had consumed alcohol $(\mathrm{M}=2.56, \mathrm{SD}=.65 ; \mathrm{M}=2.33, \mathrm{SD}=.65$, respectively).

Table 2. Black first-year college students sum mean score of expectancy subscales and individual items $(\mathrm{N}=307)$.

\begin{tabular}{|l|c|c|}
\hline & M & SD \\
\hline Four factor scale & & .70 \\
\hline Sociability and risk & 2.52 & 1.11 \\
\hline I would take risks & 2.39 & 1.02 \\
\hline I would be courageous* & 2.41 & 1.10 \\
\hline I would be loud, boisterous, or noisy & 2.55 & 1.05 \\
\hline I would be brave and daring* & 2.50 & 1.02 \\
\hline I would act aggressively & 1.90 & 1.11 \\
\hline It would be easier to talk to people* & 2.45 & 1.09 \\
\hline I would act sociable * & 2.68 & .74 \\
\hline Cognitive and behavioral impairment & 2.71 & 1.00 \\
\hline I would feel dizzy & 2.94 & .99 \\
\hline I would be clumsy & 3.10 & 1.08 \\
\hline I would feel guilty & 2.37 & .99 \\
\hline I would feel moody & 2.41 & .88 \\
\hline Sexuality & 1.86 & 1.06 \\
\hline I would enjoy sex more* & 2.01 & .91 \\
\hline I would be a better lover* & 1.70 & .88 \\
\hline Tension reduction & 2.30 & .99 \\
\hline I would feel peaceful* & 2.33 & .97 \\
\hline I would feel calm* & 2.27 & .68 \\
\hline Two factor scale & & .68 \\
\hline Positive expectancies & 2.31 & 2.52 \\
\hline Negative expectancies & & \\
\hline
\end{tabular}

This table presents the mean and standard deviation for each item and 2-factor and 4-factor scale. Individual items denoted with a * are positive expectancies.

There were significant mean differences on the sexuality subscale between those who had ever had sex and those who had not $(\mathrm{t}(289)=-2.82, p=.005)$, with sexually experienced students reporting higher mean scores compared to students who reported never having sex $(\mathrm{M}=1.97$, $\mathrm{SD}=.91$, vs. $\mathrm{M}=1.68, \mathrm{SD}=.77)$. Similarly, students who had ever had a hookup had significantly higher mean scores $(\mathrm{M}=2.12, \mathrm{SD}=.91)$ than those who had not $(\mathrm{M}=1.72, \mathrm{SD}=$ .82) $(\mathrm{t}(289)=-3.84, p<.001)$. The 2 -factor scale also showed significant mean differences in positive expectancies, student who had ever had a hookup had higher mean scores $(\mathrm{M}=2.57$, $\mathrm{SD}=.66)$ than those who had not $(\mathrm{M}=2.17, \mathrm{SD}=.66)(\mathrm{t}(281)=4.81, p<.001)$. There were no significant differences in positive or negative expectancies by sexual behaviors or in negative expectancies by participation in hookups.

In the logistic regression, there were no significant associations between the 2-factor and 4-factor AOE scales and lifetime or 30-day alcohol use. 


\section{Discussion}

The purpose of this analysis was to examine the AOEs of Black first-year college students, how AOEs are related to behaviors, and whether AOEs predict alcohol use. Overall, Black students did not hold many positive AOEs (e.g., tension reduction, sexual enhancement, being more social). Thus, despite there being statistically significant differences in the results, there was little actual differences in the mean scores. Notably, Black sexual minority students were more likely to expect positive expectancies in both 2-factor and 4-factor analyses, than Black heterosexual students.

Only $7.5 \%$ of Black first-year college students engaged in heavy episodic drinking, compared to $42 \%$ in a national sample. ${ }^{6}$ Thus, our findings support previous research that Black college students are less likely to engage in heavy drinking behaviors compared to their White counterparts. ${ }^{15}$ There was little variation in AOEs mean scores; the highest mean score was on behavioral and cognitive impairment. This finding suggests that even Black college students with no experience with alcohol use expect that alcohol will result in more negative consequences (e.g., becoming dizzy, clumsy, guilty or moody) than positive ones (e.g., make them more social, enhance sexual encounters). In addition to the listed negative expectancies, prior work has shown that Black college students expect other negative alcohol expectancies such as getting in trouble with campus authorities and reinforcing negative substance use stereotypes held by White students about Black students that attend PWIs. ${ }^{19,46}$ At PWIs, Black students report needing to represent their race and risk being stereotyped if they consume alcohol, while White students do not have this burden in a White space. ${ }^{22,46}$ The endorsement of negative expectancies in this analysis helps explain lower drinking behaviors as Black first-year college students may not want to risk behavioral or cognitive impairment associated with alcohol.

Contrary to previous research, our findings did not indicate significant gender differences in AOEs. However, there were significant differences by sexual orientation. Black sexual minority students may feel elevated discrimination due to the intersecting oppressions of race, gender, and sexual orientation resulting in higher alcohol use. ${ }^{47}$ In our sample, sexual minority students had significantly higher expectations of alcohol increasing their desire to take risks and be social as well as having more positive outcomes compared to heterosexual students. For these students, alcohol may serve as "liquid courage" to interact with others and possibly buffer the effects of discrimination that they may face in social settings as well as allow them to feel a part of the larger college culture. ${ }^{48-50}$ For students who are beginning to explore their sexuality, they may use alcohol as a strategy to talk to prospective partners of the same sex and/or engage in sexual behaviors. Exploring the intersection of race, gender, and sexual orientation further illuminates differences in AOEs and alcohol use which can be used to inform culturally relevant interventions.

The lowest mean AOEs score was on the sexuality subscale. Overall, students did not feel that alcohol would enhance their sexual experiences. However, students who reported ever having sex, hooking up, or consuming alcohol had higher mean scores on these subscales than those who did not. The low number of people who have engaged in these behaviors in the present sample supports previous research suggesting Black college students are less likely to engage in 
casual sex and hookups compared to their White peers. ${ }^{25,51}$ As Black students tend to have lower rates of drinking, ${ }^{15}$ it is crucial to reinforce the notion that alcohol does not enhance sexual experiences for students who do drink. The overall low mean score on the sexuality subscale could be attributed to the low number of students who participated in these specific sexual behaviors or it might be possible that students do not feel that they need alcohol to have pleasurable sexual experiences.

Finally, we saw that AOEs were not a predictor of ever drinking alcohol or alcohol use in the last 30 days. This suggests that there may be better predictors of alcohol use among Black first-year college students such as norms around alcohol use and sexual behavior. Thus, if alcohol interventions contain modules related to alcohol expectancies, they may not be effective for Black college students since it is not a significant predictor of alcohol use. As research highlights the role of injunctive (the perceived approval of or attitudes about drinking) and descriptive norms (the perception of other's quantity and frequency of drinking) on college students' alcohol use, ${ }^{52-54}$ future research should explore the influence of norms on Black college students' alcohol use.

\section{Limitations}

The results need to be considered within the limitations of the study. First, in our sample fewer students reported engaging in alcohol use and sexual behaviors when compared to the national averages. As such our results need to be interpreted with that in mind. ${ }^{6}$

Second, it is possible that a more culturally relevant expectancies scale is needed when conducting studies with Black and other racial minority students. While the B-CEOA scale captured important alcohol outcome expectancies, there may be other expectancies specific to Black students that affect alcohol use and sexual behaviors. ${ }^{22,27,46,55}$ Qualitative research on a sample of Black women has illuminated expectancies that are more comprehensive than captured by the subscales including to: increase sexual desire and sexual power and as an excuse to participate in sexual behaviors they would not do sober. ${ }^{27}$ Further, the measures of tension reduction could be expanded to include expectancies that Black college students endorsed in previous research such as "alcohol will help me cope," "will get me out of a negative mood," "will allow me to escape reality," or "will reduce my stress."

Third, due to a limited number of students reporting alcohol use prior to a hook up or sex, we were unable to analyze if sexuality subscale predicted these behaviors. This limited our ability to assess the relationship between AOEs and sexual behaviors.

Fourth, although we were able to examine AOEs among Black sexual minority students, there was a small number in this sample which presents challenges when trying to generalize to larger populations. Similarly, we were not able to look at AOEs for transgender students who have higher rates of alcohol consumption. ${ }^{38}$ Social identities are important predictors of alcohol use, thus a focus on identities such as race, gender, and sexual orientation as well as the potential influence of other identities (e.g., Greek affiliation and religious identity) is warranted. Future research should continue to explore the role of these intersecting identities on AOEs, alcohol consumption, and sexual behaviors. 
Finally, none of the participating universities were historically Black colleges or universities (HBCUs). Little is known about how AOEs may vary between Black college students who attend PWIs and those who attend HBCUs. Black college students often drink as a response to racism and to reduce stress at PWIs. HBCUs offer a different and often more nurturing environment for Black students so their expectations of alcohol use may be different. ${ }^{16,17}$

\section{Translation to Health Education Practice}

First-year college students are often mandated to participate in alcohol interventions which focus on addressing universal risk and protective factors for college students but are less effective at reducing alcohol use among Black students. ${ }^{15}$ A traditional approach to interventions, which includes delivering "one-size-fits-all" programming without examining how specific populations might not be meeting the needs of students with various intersecting identities. Our results highlight the importance of ensuring that health education interventions consider the unique experiences of Black college students. Given the differences in both alcohol use and STI rates by race, gender, and sexual orientation, ${ }^{21,28}$ differential messaging may be more effective and appealing to Black students, especially those who are highest need (e.g., participate in heavy episodic drinking or sexual minorities). ${ }^{58}$ Since Black college students reported lower than average rates of overall and heavy alcohol use, interventions could focus on delaying the onset of alcohol initiation and reducing higher risk drinking behaviors among lower risk students. This focus could result in a decrease in immediate (e.g., condomless sexual behaviors) and longer term (e.g., alcohol dependency) consequences across their lifetime. ${ }^{7,8}$

Researchers note that only providing interventions to high-risk individuals is not sufficient in addressing the broader negative alcohol use outcomes among college students. ${ }^{59}$ Thus, it is crucial that alcohol interventions are designed to be more culturally relevant and tailored to reduce alcohol use and sexual health disparities among Black students. ${ }^{47,60}$ As such health educators should: (1) consider the behaviors and expectancies of college students focused on the intersection of race, gender, and sexual orientation, (2) address motivations to abstain or engage in alcohol use, and (3) include specific protective factors such as cultural values, religiosity, and family connectedness as well as consider the unique needs of multi-marginalized students to promote health for all students. ${ }^{7}$

\section{Funding}

This research was supported with funding from the National Institute on Alcohol Abuse and Alcoholism (NIAAA) [\#R01 AA02293]. National Institute on Drug Abuse [P50 DA039838] and the National Center for Advancing Translational Sciences [awards UL1 TR000127 and TR002014].

\section{References}

1. Fromme K, Corbin WR, Kruse MI. Behavioral risks during the transition from high school to college. Dev Psychol. 2008;44(5):1497-1504. doi:10.1037/a0012614. [Google Scholar] 
2. Nguyen N, Walters ST, Wyatt TM, DeJong W. Use and correlates of protective drinking behaviors during the transition to college: analysis of a national sample. Addict Behav. 2011;36(10):1008-1014. doi:10.1016/j.addbeh.2011.06.002. [Google Scholar]

3. National Institute of Alcohol Abuse and Alcoholism. NIAAA council approves definition of binge drinking. NIAAA

Newsl. 2004;3:4. https://pubs.niaaa.nih.gov/publications/Newsletter/winter2004/Newsletter Number3.pdf. [Google Scholar]

4. Del Boca FK, Darkes J, Greenbaum PE, Goldman MS. Up close and personal: temporal variability in the drinking of individual college students during their first year. $J$ Consult Clin Psychol. 2004;72(2):155-164. doi:10.1037/0022-006X.72.2.155. [Google Scholar]

5. Mounts NS. Contributions of parenting and campus climate to freshmen adjustment in a multiethnic sample. J Adolesc Res. 2004;19(4):468-491.

doi:10.1177/0743558403258862. [Google Scholar]

6. Weitzman ER, Nelson TF, Wechsler H. Taking up binge drinking in college: the influences of person, social group, and environment. J Adolesc Health. 2003;32(1):26-35. doi:10.1016/S1054-139X(02)00457-3. [Google Scholar]

7. Nasim A, Belgrave FZ, Jagers RJ, Wilson KD, Owens K. The moderating effects of culture on peer deviance and alcohol use among high-risk African-American adolescents. $J$ Drug Educ. 2007;37(3):335-363. doi:10.2190/DE.37.3.g. [Google Scholar]

8. Raj A, Reed E, Santana MC, et al. The associations of binge alcohol use with HIV/STI risk and diagnosis among heterosexual African American men. Drug Alcohol Depend. 2009;101(1-2):101-106. doi:10.1016/j.drugalcdep.2008.11.008. [Google Scholar]

9. Kugler KC, Wyrick DL, Tanner AE, et al. Using the Multiphase Optimization Strategy (MOST) to develop an optimized online STI preventive intervention aimed at college students: description of conceptual model and iterative approach to optimization. In: Collins LM, ed. Optimization of Behavioral, Biobehavioral, and Biomedical Interventions. New York, NY: Springer; 2018:1-21. [Google Scholar]

10. Krieger H, Young CM, Anthenien AM, Neighbors C. The epidemiology of binge drinking among college-age individuals in the United States. Alcohol Res Curr Rev. 2018;39:23-30. [Google Scholar]

11. Jones BT, Corbin W, Fromme K. A review of expectancy theory and alcohol consumption. Addiction. 2001;96(1):57-72. doi:10.1046/j.1360-0443.2001.961575.x. [Google Scholar]

12. Brown SA, Goldman MS, Inn A, Anderson LR. Expectations of reinforcement from alcohol: their domain and relation to drinking patterns. J Consult Clin Psychol. 1980;48(4):419-426. doi:10.1037/0022-006X.48.4.419. [Google Scholar]

13. Gilmore AK, George WH, Nguyen HV, Heiman JR, Davis KC, Norris J. Influences of situational factors and alcohol expectancies on sexual desire and arousal among heavyepisodic drinking women: acute alcohol intoxication and condom availability. Arch Sex Behav. 2013;42(6):949-959. doi:10.1007/s10508-013-0109-x. [Google Scholar] 
14. Greenbaum PE, Del Boca FK, Darkes J, Wang C-P, Goldman MS. Variation in the drinking trajectories of freshmen college students. J Consult Clin Psychol. 2005;73(2):229-238. doi:10.1037/0022-006X.73.2.229. [Google Scholar]

15. Brawner RD. Alcohol abuse, Why not an issue for African American college students? https://pdfs.semanticscholar.org/0c19/641fa0da539eabc3df8032ca4b790c1a9f22.p df. Published 2014. Accessed December 4, 2018. [Google Scholar]

16. Carter-Edwards L, Godette DC, White SS, Tyson W. A conceptual framework for studying alcohol intake and blood pressure on historically Black college and university campuses. $J$ Drug Educ. 2009;39(2):149-165. doi:10.2190/DE.39.2.c. [Google Scholar]

17. Kapner DA Alcohol and Other Drug Use at Historically Black Colleges and Universities. https://files.eric.ed.gov/fulltext/ED537617.pdf. Published 2008. Accessed December 4, 2018. [Google Scholar]

18. Laird T, Shelton A, Jefferson J. Social norms of alcohol use at historically Black university. Ala Couns Assoc J. 2007;33:19-26. [Google Scholar]

19. Peralta RL. Raced and gendered reactions to the deviance of drunkenness: a sociological analysis of race and gender disparities in alcohol use. Contemp Drug Prob. 2010;37(3):381415. doi:10.1177/009145091003700303. [Google Scholar]

20. Borsari B, Murphy JG, Barnett NP. Predictors of alcohol use during the first year of college: implications for prevention. Addict Behav. 2007;32(10):2062-2086. doi:10.1016/j.addbeh.2007.01.017. [Google Scholar]

21. Paschall MJ, Bersamin M, Flewelling RL. Racial/Ethnic differences in the association between college attendance and heavy alcohol use: a national study. J Stud Alcohol. 2005;66(2):266-274. doi:10.15288/jsa.2005.66.266. [Google Scholar]

22. Peralta RL. Race and the culture of college drinking: an analysis of White privilege on a college campus. In: Palacios WR, ed. Cocktails \& Dreams: An Interpretive Perspective on Substance Use. New Jersey, NJ: Prentice-Hall; 2005:127-141. [Google Scholar]

23. Banks D, Winningham R, Wu W, Zapolski T. Examination of the indirect effect of alcohol expectancies on ethnic identity and adolescent drinking outcomes. Am J Orthopsychiatry. 2019;89(5):600-608. doi:10.1037/ort0000390. [Google Scholar]

24. Fielder RL, Carey MP. Prevalence and characteristics of sexual hookups among firstsemester female college students. J Sex Marital Ther. 2010;36(4):346-359. doi:10.1080/0092623X.2010.488118. [Google Scholar]

25. Kuperberg A, Padgett JE. The role of culture in explaining college students' selection into hookups, dates, and long-term romantic relationships. J Soc Pers Relat. 2016;33(8):10701096. doi:10.1177/0265407515616876. [Google Scholar]

26. Cooper ML. Alcohol use and risky sexual behavior among college students and youth: evaluating the evidence. J Stud Alcohol Suppl. 2002;(14):101-117. doi:10.15288/jsas.2002.s14.101. [Google Scholar] 
27. Hutton HE, McCaul ME, Norris J, Valliant JD, Abrefa-Gyan T, Chander G. Sex-related alcohol expectancies among African American women attending an urban STI clinic. $J$ Sex Res. 2015;52(5):580-589. doi:10.1080/00224499.2014.931336. [Google Scholar]

28. Centers for Disease Control and Prevention. Health disparities in HIV/AIDS, viral hepatitis, STDs, and TB- African

Americans/blacks. https://www.cdc.gov/nchhstp/healthdisparities/africanamericans.html. Published December 3, 2018. Accessed December 4, 2018. [Google Scholar]

29. Crenshaw K. Mapping the margins: intersectionality, identity, politics, and violence against women of color. Stanford Law Rev. 1991;43(6):1241-1299. doi:10.2307/1229039. [Google $\underline{\text { Scholar] }}$

30. Bowleg L. The problem with the phrase women and minorities: intersectionality -an important theoretical framework for public health. Am J Public Health. 2012;102(7):12671273. doi:10.2105/AJPH.2012.300750. [Google Scholar]

31. Clark C, Matthew D, Burns V. Power, privilege and justice: intersectionality as human rights? Int J Hum Rights. 2018;22(1):108-126.

doi:10.1080/13642987.2017.1390333. [Google Scholar]

32. Carliner H, Delker E, Fink D, et al. Racial discrimination, socioeconomic position, and illicit drug use among US blacks. Soc Psychiatry Psychiatr Epidemiol. 2016;51(4):551-560. doi:10.1007/s00127-016-1174-y. [Google Scholar]

33. Bradizza CM, Reifman A, Barnes GM. Social and coping reasons for drinking: predicting alcohol misuse in adolescents. J Stud Alcohol. 1999;60(4):491-499. doi:10.15288/jsa.1999.60.491. [Google Scholar]

34. O'Hara RE, Boynton MH, Scott DM, et al. Drinking to cope among African American college students: an assessment of episode-specific motives. Psychol Addict Behav. 2014;28(3):671-681. doi:10.1037/a0036303. [Google Scholar]

35. Wade J, Peralta RL. Perceived racial discrimination, heavy episodic drinking, and alcohol abstinence among African American and White college students. J Ethn Subst Abuse. 2017;16(2):165-180. doi:10.1080/15332640.2015.1113152. [Google Scholar]

36. Cooper ML, Krull JL, Agocha VB, et al. Motivational pathways to alcohol use and abuse among Black and White adolescents. J Abnorm Psychol. 2008;117(3):485-501. doi:10.1037/a0012592. [Google Scholar]

37. Reed E, Prado G, Matsumoto A, Amaro H. Alcohol and drug use and related consequences among gay, lesbian and bisexual college students: role of experiencing violence, feeling safe on campus, and perceived stress. Addict Behav. 2010;35(2):168-171. doi:10.1016/j.addbeh.2009.09.005. [Google Scholar]

38. Coulter RWS, Blosnich JR, Bukowski LA, Herrick AL, Siconolfi DE, Stall RD. Differences in alcohol use and alcohol-related problems between transgender- and nontransgenderidentified young adults. Drug Alcohol Depend. 2015;154:251-259. doi:10.1016/j.drugalcdep.2015.07.006. [Google Scholar] 
39. Garneau C, Olmstead SB, Pasley K, Fincham FD. The role of family structure and attachment in college student hookups. Arch Sex Behav. 2013;42(8):1473-1486. doi:10.1007/s10508-013-0118-9. [Google Scholar]

40. Lewis MA, Rees M, Logan DE, Kaysen DL, Kilmer JR. Use of drinking protective behavioral strategies in association to sex-related alcohol negative consequences: the mediating role of alcohol consumption. Psychol Addict Behav. 2010;24(2):229-238. doi:10.1037/a0018361. [Google Scholar]

41. Siebert DC, Wilke DJ, Delva J, Smith MP, Howell RL. Differences in African American and White college students' drinking behaviors: consequences, harm reduction strategies, and health information sources. J Am Coll Health. 2003;52(3):123-129. doi:10.1080/07448480309595734. [Google Scholar]

42. Ham LS, Stewart SH, Norton PJ, Hope DA. Psychometric assessment of the comprehensive effects of alcohol questionnaire: comparing a brief version to the original full scale. $J$ Psychopathol Behav Assess. 2005;27(3):141-158. doi:10.1007/s10862-005-0631-9. [Google $\underline{\text { Scholar] }}$

43. Ham LS, Wang Y, Kim SY, Zamboanga BL. Measurement equivalence of the brief comprehensive effects of alcohol scale in a multiethnic sample of college students. J Clin Psychol. 2013;69(4):341-363. doi:10.1002/jclp.21904. [Google Scholar]

44. Ham LS, Hope DA. Incorporating social anxiety into a model of college problem drinking: replication and extension. Psychol Addict Behav. 2006;20(3):348-355. doi:10.1037/0893164X.20.3.348. [Google Scholar]

45. Zamboanga BL, Schwartz SJ, Ham LS, Borsari B, Van Tyne K. Alcohol expectancies, pregaming, drinking games, and hazardous alcohol use in a multiethnic sample of college students. Cognit Ther Res. 2010;34(2):124-133. doi:10.1007/s10608-009-9234-1. [Google Scholar]

46. Peralta RL, Steele JL. On drinking styles and race: a consideration of the socio-structural determinants of alcohol use behavior. J Ethn Subst Abuse. 2009;8(2):146-162. doi:10.1080/15332640902897024. [Google Scholar]

47. Demant D, Oviedo-Trespalacios O, Carroll J-A, et al. Do people with intersecting identities report more high-risk alcohol use and lifetime substance use? Int J Public Health. 2018;63(5):621-630. doi:10.1007/s00038-018-1095-5. [Google Scholar]

48. Coulter RWS, Marzell M, Saltz R, Stall R, Mair C. Sexual-orientation differences in drinking patterns and use of drinking contexts among college students. Drug Alcohol Depend. 2016;160:197-204. doi:10.1016/j.drugalcdep.2016.01.006. [Google Scholar]

49. Cáceres CF, Cortiñas JI. Fantasy island: an ethnography of alcohol and gender roles in a Latino gay bar. J Drug Issues. 1996;26(1):245-260. doi:10.1177/002204269602600113. [Google Scholar]

50. Peralta RL. "Alcohol allows you to not be yourself": toward a structured understanding of alcohol use and gender difference among gay, lesbian, and heterosexual youth. J Drug Issues. 2008;38(2):373-399. doi:10.1177/002204260803800201. [Google Scholar] 
51. Owen JJ, Rhoades GK, Stanley SM, Fincham FD. "Hooking up" among college students: demographic and psychosocial correlates. Arch Sex Behav. 2010;39(3):653-663. doi:10.1007/s10508-008-9414-1. [Google Scholar]

52. Turrisi R, Padilla KK, Wiersma KA. College student drinking: an examination of theoretical models of drinking tendencies in freshmen and upperclassmen. $J$ Stud Alcohol. 2000;61(4):598-602. doi:10.15288/jsa.2000.61.598. [Google Scholar]

53. Hartzler B, Fromme K. Heavy episodic drinking and college entrance. J Drug Educ. 2003;33(3):259-274. doi:10.2190/2L2X-F8E1-32T9-UDMU. [Google Scholar]

54. Perkins HW, Craig DW. A successful social norms campaign to reduce alcohol misuse among college student-athletes. J Stud Alcohol. 2006;67(6):880-889. doi:10.15288/jsa.2006.67.880. [Google Scholar]

55. Currin JM, Croff JM, Hubach RD, Miller BM. Using sex-related alcohol expectancies to predict condom use among a general sample of men and women in the United States. Sex Cult. 2017;21(2):459-470. doi:10.1007/s12119-016-9399-1. [Google Scholar]

56. Griffin KW, Botvin GJ, Nichols TR, Scheier LM. Low perceived chances for success in life and binge drinking among inner-city minority youth. J Adolesc Health. 2004;34(6):501-507. doi:10.1016/S1054-139X(03)00390-2. [Google Scholar]

57. Neff JA. Solitary drinking, social isolation, and escape drinking motives as predictors of high quantity drinking, among Anglo, African American and Mexican American males. Alcohol Alcohol. 1997;32(1):33-41. doi:10.1093/oxfordjournals.alcalc.a008232. [Google Scholar]

58. Scott-Sheldon LAJ, Carey KB, Elliott JC, Garey L, Carey MP. Efficacy of alcohol interventions for first-year college students: a meta-analytic review of randomized controlled trials. J Consult Clin Psychol. 2014;82(2):177-188. doi:10.1037/a0035192. [Google Scholar]

59. Neale ZE, Salvatore JE, Cooke ME, et al. The utility of a brief web-based prevention intervention as a universal approach for risky alcohol use in college students: evidence of moderation by family history. Front Psychol. 2018;9:747. doi:10.3389/fpsyg.2018.00747. [Google Scholar]

60. Vardeman-Winter J, Jiang H, Tindall NTJ. Information-seeking outcomes of representational, structural, and political intersectionality among health media consumers. $J$ Appl Commun Res. 2013;41(4):389-411. doi:10.1080/00909882.2013.828360. [Google Scholar] 